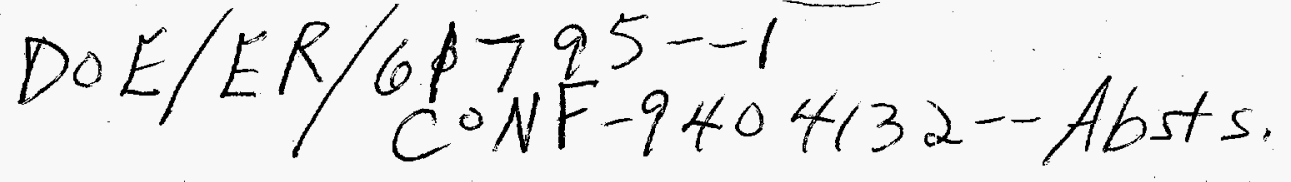

Ann. Hum. Genet. $(1994), 58,177-250$

Printed in Grent Britain

\title{
REPORT on the Third International Workshop on Chromosome 9
}

held at Queens' College, Cambridge, UK, 9-11 April, 1994

Report compiled by: S. POVEY ${ }^{1}$, J.ARMOUR ${ }^{2}$, P.FARNDON ${ }^{3}$, J. L. HAINES ${ }^{4}$, M. KNOWLES ${ }^{5}$, F. OLOPADE ${ }^{6}$, A. PILZ ${ }^{7}$, J. A. WHITE ${ }^{1}$, members of the Utah Genome

Center Genetic Marker and Mapping group ${ }^{8}$ AND D. J. KWIATKOWSKI ${ }^{9}$

${ }^{1}$ MRC Human Biochemical Genetics Unit, Galton Laboratory, University College London, Wolfson House, 4 Stephenson Way, London, NW1 2HE UK

${ }^{2}$ University of Leicester, Department of Genetics, Adrian Building, University Road, Leicester, LE1 7RH UK

${ }^{3}$ Clinical Genetics Unit, Birmingham Maternity Hospital, Edgbaston, Birmingham B15 2TG UK

4 Massachusetts General Hospital, Neurogenetics Laboratory, Building 149, 6th Floor, 13th Street, Charlestown, MA 02129, USA

5 Marie Curie Research Institute, The Chart, Oxted, Surrey, RH8 OTL UK

${ }^{6}$ University of Chicago Medical Center, 5841 S. Maryland Avenue, Box 420, Chicago, Illinois 60637-1470, USA

7 Genetics and Biometry Dept, University College London, The Galton Laboratory, 4 Stephenson Way, London NW1 2HE UK

${ }^{8}$ Department of Human Genetics, Eccles Institute of Human Genetics, University of Utah, Salt Lake City, Utah 84112, USA

${ }^{9}$ Experimental Medicine Division, Brigham and Women's Hospital, 221 Longwood Avenue, Boston, MA 02115, USA

The Third International Workshop on human chromosome 9 was held at Queens' College, Cambridge 9-11 April, 1994. The meeting was attended by 74 participants from 12 countries. On the morning of 12 April a satellite meeting was held on Tuberous Sclerosis, and because of its relevance to chromosome 9 a summary of this meeting is also presented within this report. Sixty-four abstracts were received and the data presented on posters.

As before after a brief presentation of interests and highlighted results the workshop divided into several groups, each with the task of producing a report. The division consisted of a group with global interests, four regional groups 9p, 9q11-q21, 9q22-q33 and 9q33-qter, a group interested in mapping putative suppressor genes in ovarian and bladder cancer and a comparative mapping group. There was also discussion of resources, both physical and informatic.

The amount of information on chromosome 9 has inereased greatly in the past two years and it is clear that the integration of different types of information and the display of such information is an urgent problem. At this meeting two possible systems were explored, SIGMA and $\mathrm{ldb}$. As described in the global group report an attempt was made to enter all mapping information into SIGMA, a program developed by Michael Cinkosky at Los Alamos. Within the text of this report a name without a date refers to an abstract at this meeting (see end of report). A name with a date refers to a publication listed in the references and these are in general confined to very recent or 'in press' references. A verbal communication at the meeting is identified as a personal communication. For authoritative referencing of published information

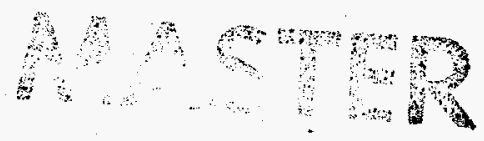


and also for all primer sequences (except a few actually listed in the abstracts) the reader should consult GDB. The proceedings of the two previous workshops have been published and are listed in the references (Povey et al. 1992. Kwiatkowski et al. 1993a). It was decided that a fourth workshop would be held in about a year's time. Dr Margaret Pericak-Vance offered to host this at Duke Lniversity, North Carolina.

As in previous years there was considerable debate about the importance of producing sexspecific genetic maps. It is recognized that a sex-averaged chromosome does not exist and several individual workers had indeed considered the sexes separately but it was not practical to attempt integration of sex-specific data into the consensus over the time of the workshop. Collins et al. presented a comprehensive integrated map of chromosome 9 generated by ldb including over 220 loci which estimated the genetic length (D9S143-D9S11) as $117 \mathrm{eN}$ in males and $160 \mathrm{cM}$ in females, with a marked increase in male recombination near pter. This map together with the relevant datafiles will be available on the chromosome 9 file-server (see section on resources). Hultén has previously reported a male chiasma map of 9 suggesting a genetic length of $116 \mathrm{cM}$ with very strong interference, a finding which has been borne out by recent publications (Kwiatkowski et al. 1993b, Attwood et al. 1994) and at the meeting (Farndon et al.). Female chiasmata maps would now be possible if suitable material can be obtained (Hulten et al.). There is some suggestion that recombination is determined by position rather than sequence, since increased recombination was shown within the interstitial segments of two male carriers of translocations involving 9 (Armstrong \& Hulten).

Haines \& Kwiatkowski presented an analysis of CEPH families showing that the average number of recombinants per chromosome 9 per individual parent followed a normal distribution, with a range of 0.43 to 1.86 in males and 0.88 to 2.67 in females. In males a decrease in recombination was seen over the age of 40 years.

\section{GLOBAL MAPPING GROUP}

This group included John Armour, David Kwiatkowski, Julia White, John Attwood, Sue Povey, Maj Hultén and Andy Collins. Although the two major groups involved in global mapping projects did not attend they both contributed data. J. Weissenbach contributed unpublished primary data on 35 new Genethon markers in the CEPH families. J. Murray contributed the latest map from CHLC.

The global group concerned itself primarily with the production of maps of the whole chromosome, centred on two approaches:

(a) SIGMA

The group encouraged and facilitated the transfer of new mapping information into SIGMA, a UNIX-based mapping and display tool written by Michael Cinkosky at Los Alamos. These data were used to produce an updated SIGMA map of chromosome 9 . It should be emphasized that SIGMA uses information from both genetic and physical mapping to give an integrated map; the linkage data are mainly used to provide an initial framework, and on a smaller scale to interpolate between flanking markers of known relationship. Its main function for this workshop was to provide an overall 'best guess' relative location for as many markers as possible. The amount of data which can be entered into SIGMA is constrained only by time and 


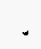




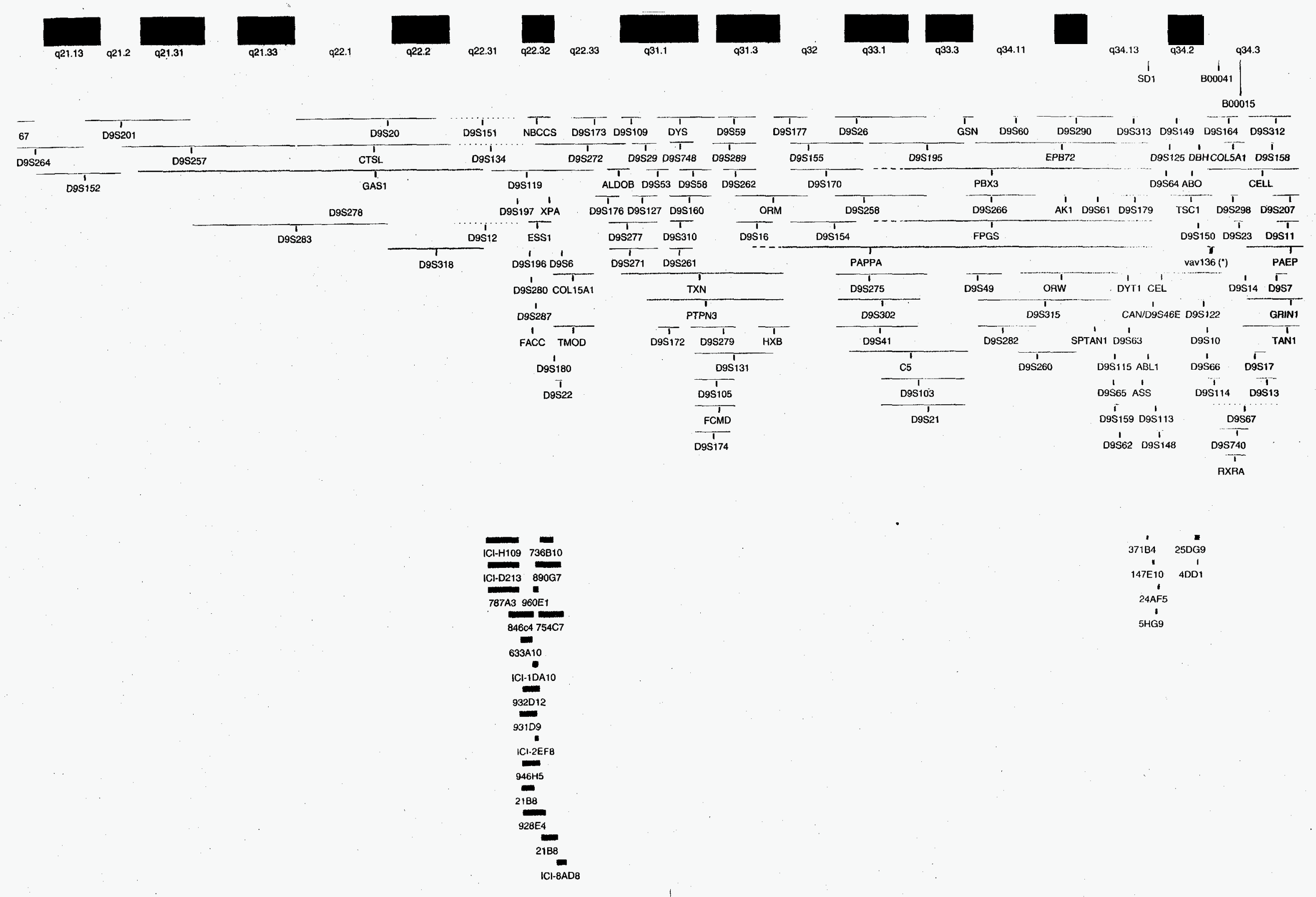





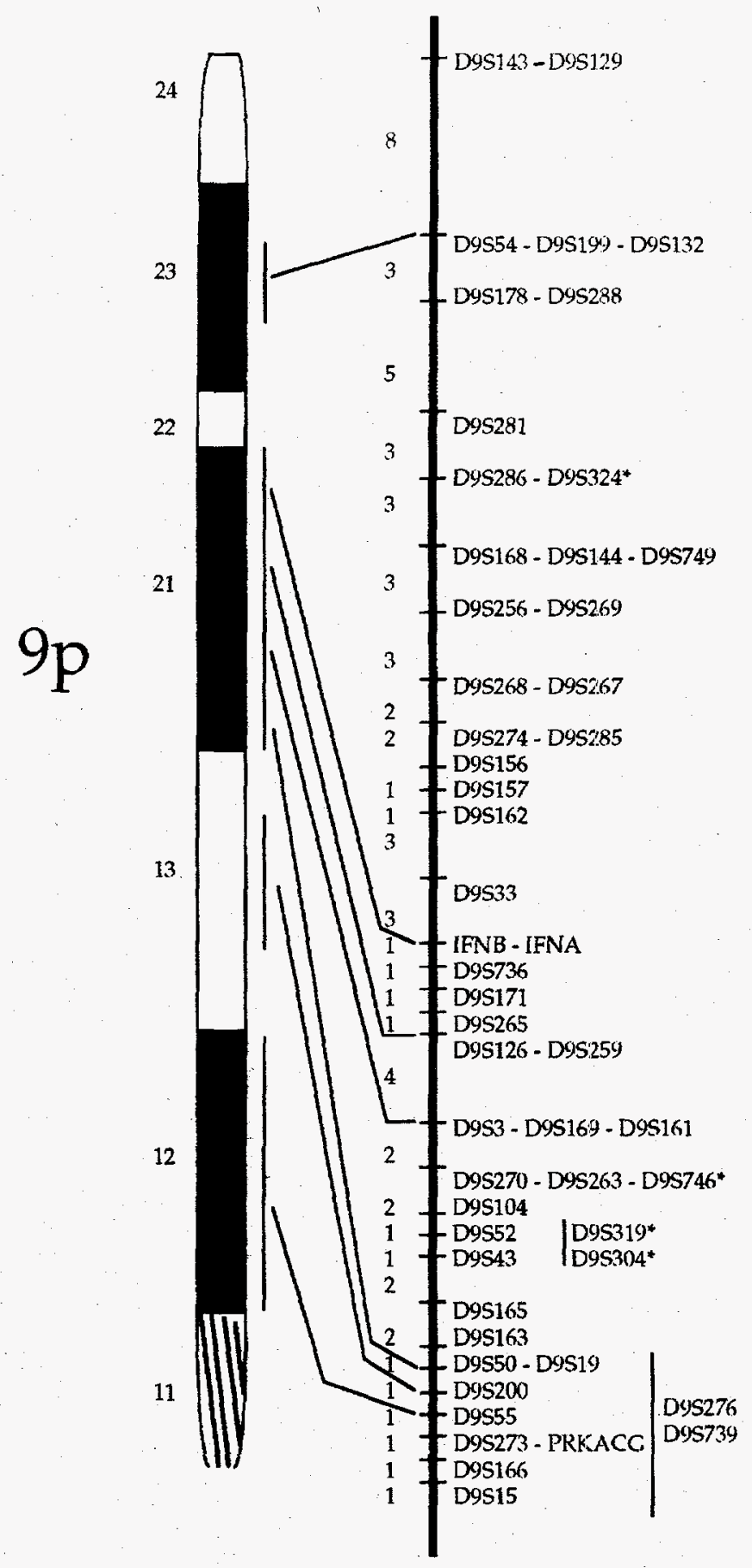

Fig. 2. The composite genetic linkage map of human chromosome $9 p$ (sex-average). The map represents a consensus linkage map based upon a variety of information, both published and unpublished. The intent is to incorporate as many markers as possible, and to use physical information when available. * denotes marker is of the tetranucleotide repeat type. The majority of markers with $S$ numbers less than 50 are RFLPs. Nearly all markers with $\mathbf{S}$ numbers greater than $\mathbf{5 0}$ are the STR type, the majority of which are GT/CA repeats. Numbers shown are consensus intermarker distances in $\mathrm{cM}$, sex-average. Additional STR markers together with relevant mapping information have been provided by the Utah Genome Center Genetic Marker and Mapping; Group (Tables 4-5), but are not shown in this figure. 


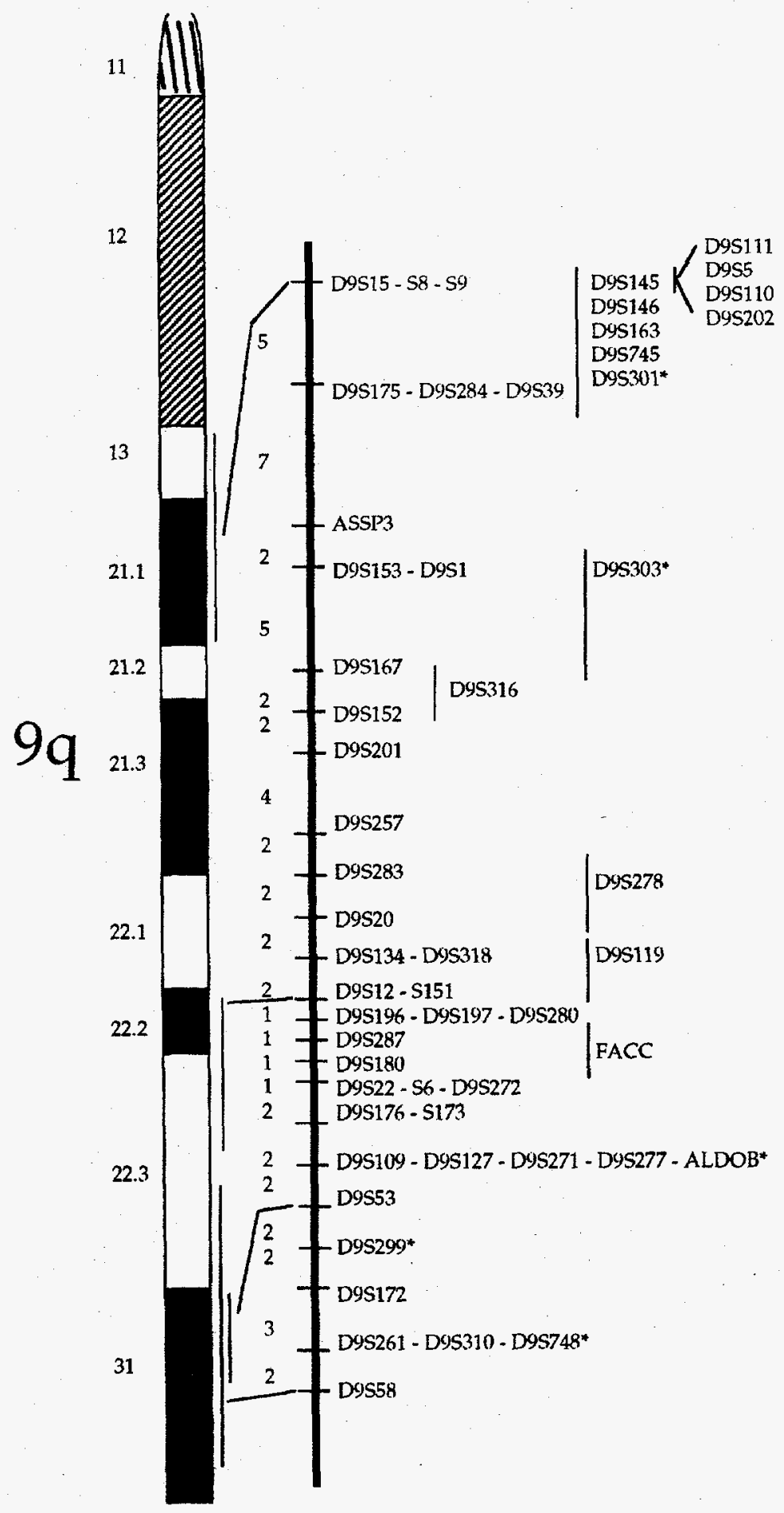

Fig. 3. The composite genetic linkage map of human chromosome 9qcen-q31 (sex-average). See legend to Fig. 2. 
resources and it should be possible to keep a 'main' version updated so that older information is never lost. The printout supplied in this report (Fig. 1) has had to be selective, concentrating especially on new data which are shown in red. The scale used does not allow fine detail so for some regions additional diagrams are needed.

(b) Genetic maps

Complementing the SIGMA map, a consensus genetic map was produced using the CEPH consortium map (Attwood et al. 1994) as a starting point. This was updated using data from Genethon (which had been subjected to preliminary analysis by John Attwood) and data from CHLC (Murray et al.). Also incorporated were new index markers provided by David Kwiatkowski (Zahn et al.) and by John Armour (Armour et al.) and further work on some markers in 9q34 (Jeremiah et al.). The genetic map shown in Figs 2, 3 and 4 is based on typing in CEPH families. Several groups have also deduced detailed regional maps from other sources and some of those results are included in the regional reportis.

Relatively few new markers could be placed conservatively and without ambiguity on the linkage map, but the updated version contains a high density of markers, the largest (sexaverage) interval being $10.5 \mathrm{cM}$, between D9S157 and IFN. The map, however, includes many additional markers which could not be placed unambiguously. The updated linkage map is presented as three figures, corresponding to $9 p$, proximal $9 q$ and distal $9 q$ (Figs 2, 3 and 4 respectively).

THE $9 \mathrm{p}$ GROUP

The report on $9 p$ was co-ordinated by Olufunmilayo Olopade, who also presented data in an abstract (Bohlander $e t$ al.). Contributors to the discussion whose data are also presented as abstracts (as first authors unless indicated) were Paul Cairns, Cathryn Lewis (Cannon-Albright et al.), Jayne Devlin, Magali Williamson, Alison Keen, Margaret Knowles (Devlin \& Knowles, Williams \& Knowles, Keen \& Knowles), Rob Furlong, Dan Grander, Pali Kaur, K. Ichimura, Michael Lynch, Charles Spruck, Joseph Wagstaff and T. Sulisalo. Other contributors included Nigel Spurr.

The $9 p$ region has generated a lot of interest because of the localization of putative tumour suppressor genes in the region. Several groups have reported homozygous deletions of $9 p$ sequences in ALL, glioma, melanoma, lung cancer, mesothelioma, head and neck cancer, and bladder cancer. Moreover, familial melanoma has been linked to this region in some families. Therefore, most of the new information came from groups interested in the tumour suppressor gene region.

A 3.0 megabase YAC contig has been constructed around the IFN gene cluster. The MTAP gene has been localized $500 \mathrm{~kb}$ from IFNA8/A1 and within the same $1400 \mathrm{~kb}$ Not1 fragment as the IFN gene cluster (Bohlander et al., Stadler et al., 1994). An STS MD59 has been mapped approximately $800 \mathrm{~kb}$ from IFNA1. This YAC contig spanning the IFN gene cluster and including at least 2 megabases centromeric to IFNA1 does not contain D9S171. Therefore, D9S171 is at least 2 megabases from the IFN gene cluster. The TS9P locus was refined to the region between MTAP and MD59, i.e. proximal to MTAP. A new marker D9S736 has been mapped $2 \mathrm{cM}$ distal to D9S171 and proximal to IFNA. MLM maps between D9S736 and D9S171 based on recombination information in 2 Utah families (Cannon-Albright $e t$ al.). In one 


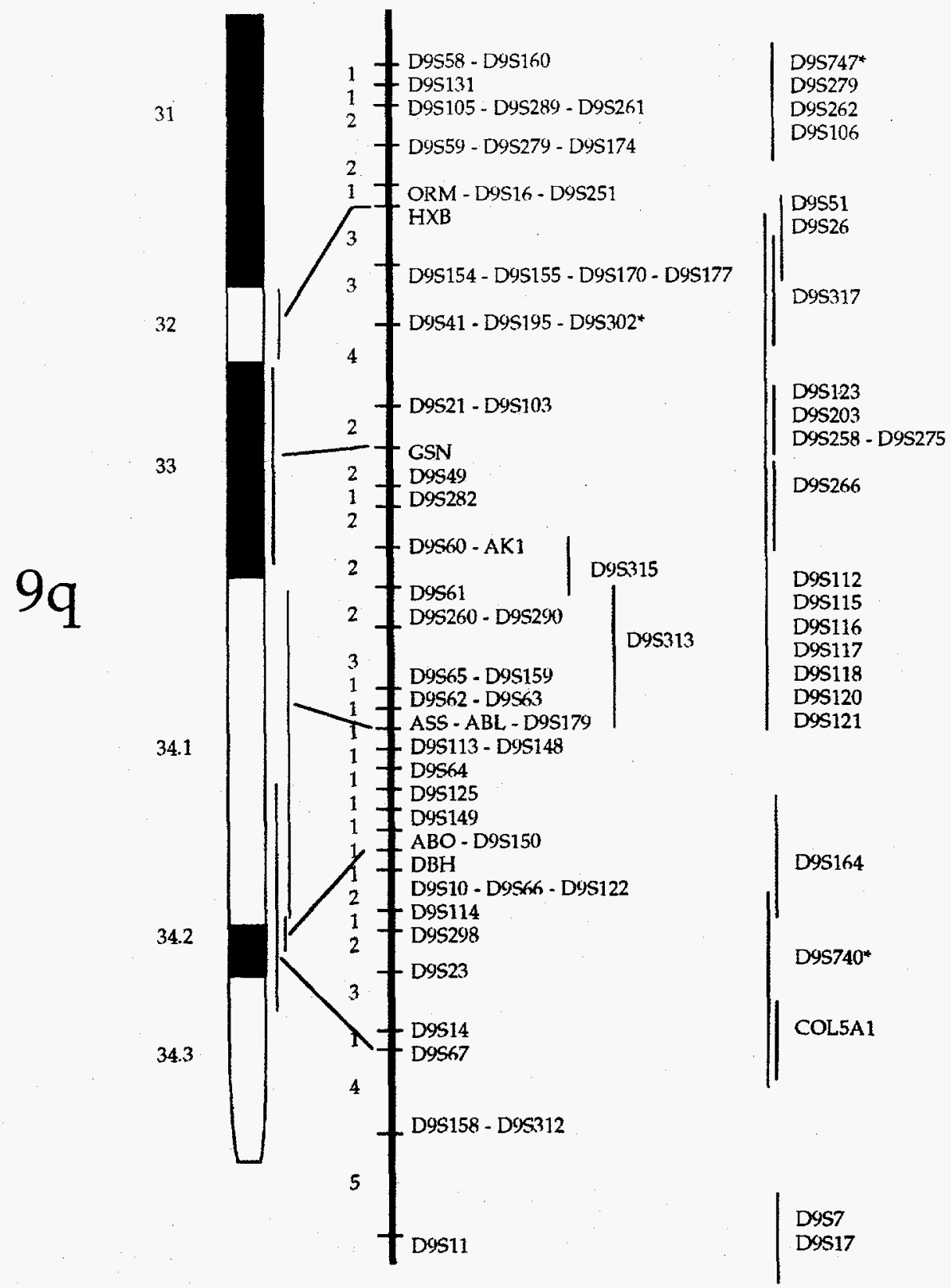

Fig. 4. The composite genetic linkage map of human chromosome 9q31-qter (sex-average). See legend to Fig. 2.

UK family MLM was mapped proximal to D9S169 (N. Spurr, personal communication). It is not clear if TS9P is the same as the MLM gene or if there are other tumour suppressor genes in the region. D9S265 has been placed in the interval between D9S171/D9S126 and MLLT3. The gene MLLT3 has been placed between D9S171 and D9S156 and has been shown to contain an unstable polymorphic trinucleotide repeat (Walker et al. 1994).

$9 \mathrm{p}^{-}$syndrome, characterized by craniosynostosis and mental retardation, has been defined to a region bordered by D9S162 and D9S286 (Wagstaff $e t$ al.). TYRP has been localized within a 
$600 \mathrm{~kb} \mathrm{YAC}$ which also contains the marker D9S267, and TYRP is proximal to D9S269 (J. Wagstaff. personal communication).

The genetic mapping of the gene for cartilage hair hypoplasia ( $\mathrm{CHH}$ ) has been refined by high resolution linkage disequilibrium analysis (in uniplex families) as well as by 8 -point linkage analysis. Both methods suggest $\mathrm{CHH}$ is very slightly proximal to D9S163 (Sulisalo et al.). Two new genes assigned to 9p24 are very low density lipoprotein receptor, VLDLR (Oka et al. 1994; Sakai et al. 1994) and a high affinity glutamate transporter provisionally designated EAAC1 (official symbol now SLC1A1) (Smith et al. 1994). A new CA repeat marker D9S749 has been mapped close to D9S144 (Furlong et al.).

A few days after the workshop, two independent groups reported the identification of mutations, deletions and rearrangements in a gene found on 9p21 previously unmapped but already described as an inhibitor of eyclin-kinase 4, in cell lines derived from a variety of tumours in which deletions of 9p21 have been found as described above (Kamb et al. 1994, Nobori et al. 1994). It is not yet clear whether cases of familial melanoma have germline mutations in the same gene.

$$
9 q 11-q 21
$$

Recent work in the region of the locus for Friedreich's ataxia, FRDA, has placed this gene proximal to the D9S5/D9S15 linkage group with the most probable order being FRDA-D9S5D9S15-qter (Doudney, St Mary's Hereditary Ataxia Group). Several markers have been added giving the order FRDA-D9S202-D9S5-D9S111-D9S15-D9S110 (Rodius et al. 1994). Three additional new markers FR7, FR8 and FR5 are thought to be proximal to FRDA (Rodius et al. 1994). Three new coding sequences have been reported, X11 and X123 between D9S111 and D9S202, and X104, approximately $40 \mathrm{~kb}$ proximal to D9S202 and probably distal to FRDA (Duclos et al. 1994). This would narrow the critical region for FRDA to about $300 \mathrm{~kb}$ (Duclos et al. 1994). There has been a suggestion from Japan of another locus determining a form of ataxia similar to Friedreich's but with some additional features including early onset and hypoalbuminaemia. This disorder showed linkage to D9S15 with a maximum lodseore of 3.4 although three recombinant events with D9S15 suggest it may not be allelic with FRDA (Tanaka et al. 1993).

A new gene GAS1, growth arresting factor, has been majpped to the region $9 q 21.3-q 22$ (Evdokiou et al. 1993, Del Sal et al. 1994) and was also localized by two colour FISH proximal to D9S12 (B. Wainwright, personal communication).

$$
9 q 22-q 33
$$

The report on this region was co-ordinated by Peter Farndon. The consensus map of this area as entered into SIGMA is shown in Fig. 1. This incorporates information from physical and genetic mapping techniques. A more detailed map of $9 \mathrm{q} 22.3$ is shown in Fig. 5 .

New assignments

COL15A1 and TMOD have both been mapped to the interval bounded by D9S180 and D9S173 (Dean et al.). Gailani et al. also presented data localizing COL15A1 distal to D9S180. TMOD (tropomodulin) is a protein which modulates the association of tropomyosin with the 
spectrin-actin complex in the membrane skeleton of erythrocytes. PTPH1, the first identified third class protein tyrosine phosphatase, whose structure suggests that it may play an important role in the regulation of cell to cell or cell to substratum interactions has been localized distal to D9S29 (Dean et al.).

Multipoint linkage analysis has placed the gene for Fukuyama congenital muscular dystrophy (FCMD) in the interval D9S58-D9S59, homozygosity mapping in consanguineous families supporting this location (Toda et al. 1993).

Refinement of locations of disease genes

Nevoid basal cell carcinoma syndrome (NBCCS, Gorlin Syndrome)

Four groups (Bare et al., Dean et al., Farndon et al., Wainwright et al.), presented information about markers proximal to NBCCS. One recombinant was reported with D9S12, and three recombinants with D9S196. There were three recombinants with D9S176 (Bare et al., Farndon et al.) and one recombinant with a closer distal marker D9S180 (Wicking et al.). NBCCS therefore maps in the interval D9S196-D9S180.

GAS1, COL15A1, TMOD, and PTPH1 were possible candidate genes for the Gorlin syndrome, but their localizations exclude them.

Multiple self healing squamous epithelioma (ESS1, Ferguson-Smith Syndrome)

Linkage analysis and haplotype data give odds of 100:1 that the gene for this syndrome also lies between D9S196 and D9S180 (Goudie et al.), a genetic distance of about $4 \mathrm{cM}$.

Fanconi anaemia complementation group $C(F A C C)$

Linkage data place the gene between D9S12/D9S196 and D9S287 (Jeremiah et al., Dean et al., Farndon et al.). Physical mapping (Morris et al.) places the gene between D9S280 and D9S287. Mutations in the FACC gene have been found in patients with Fanconi anaemia (Whitney et al. 1993; Verlander et al. 1994).

Xeroderma pigmentosum complementation group $A(X P A C)$

Barroso et al. and Morris et al. place XPAC on the physical map in the interval D9S287-D9S180. The distance between XPAC and D9S180 is estimated to be about $250 \mathrm{~kb}$ by using FISH on interphase cells (Leversha et al.).

\section{Order of markers and physical distances}

The consensus order of markers is as shown in Fig. 5. The linkage data are consensus data based on published data and data from Kwiatkowski et al. and Farndon et al.

Fluorescent in situ hybridization on interphase nuclei prepared from normal male fibroblast cultures gave a distance between D9S12 and D9S180 of about $1 \mathrm{Mb}$ (Leversha et al.). Distances between ALAD and $\mathrm{HXB}$, and between $\mathrm{HXB}$ and GSN were $1.6 \mathrm{Mb}$ and $1.5 \mathrm{Mb}$ respectively. Molecular distance estimates from FISH are in broad agreement with currently available physical mapping data. A comparison of measured distances and precise molecular distances will provide valuable insight into the conformation of the interphase chromosome. 


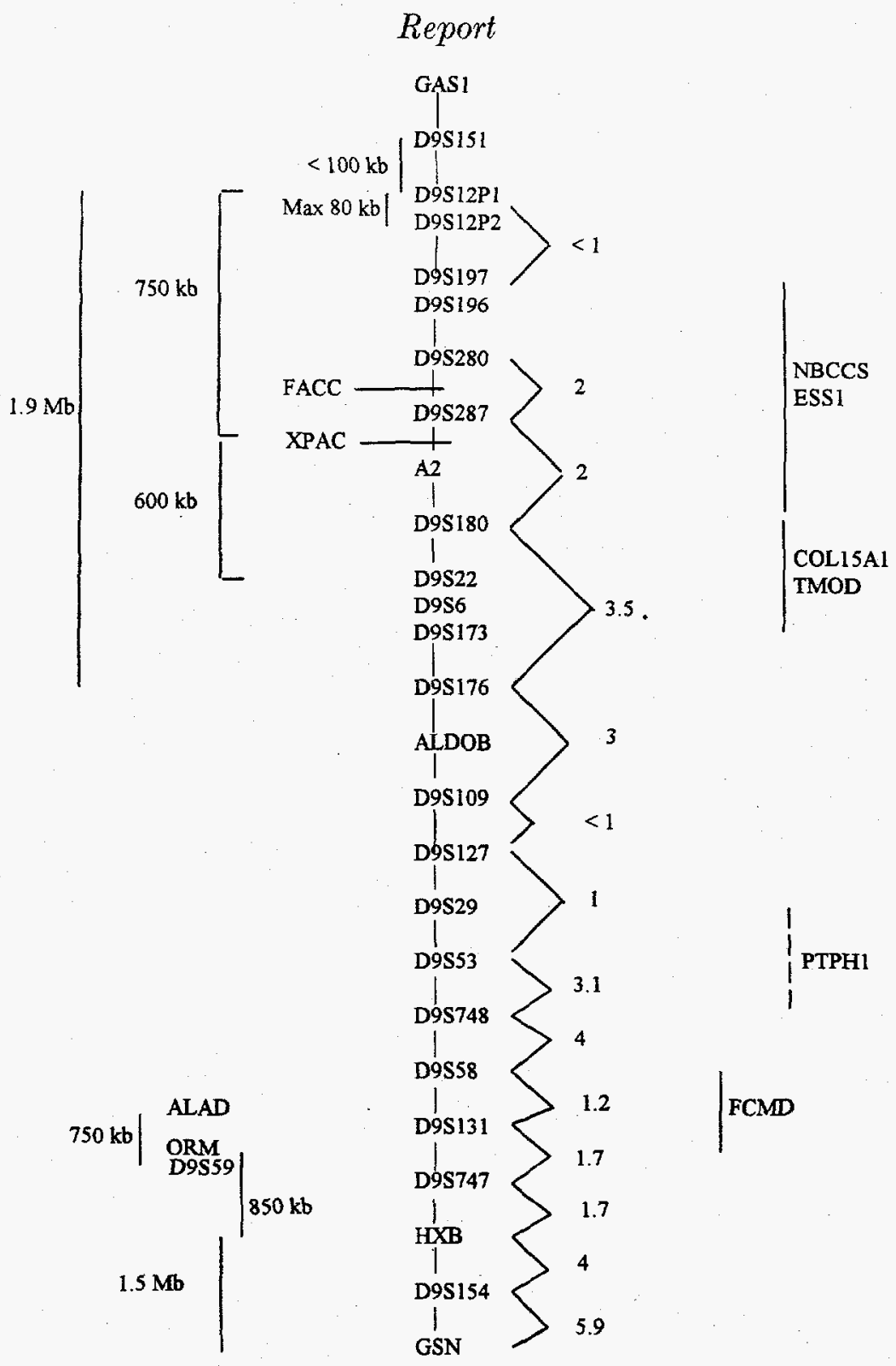

185

Fig. 5. High resolution map of 9q22.3-q33. Distances are not drawn to scale. Map distances shown to the right of the markers are in cM. These are consensus distances from data presented at the workshop, and may vary slightly from the distances on Figs 3-4 which include previously published data. Physical distances to the left of the markers are mostly from FISH data on interphase cells.

Physical data from YAC studies give a distance between D9S12 and D9S176 of about 1.9 .llb (Morris et al.).

\section{$Y A C$ contigs}

Several groups (Barroso et al., Dean et al., Morris et al., Wicking et al.) presented YA(' rontils. of the region between D9S151 and D9S176 (and formed a small committee to thar information). The sources of the YAC clones and their chromosome contents are shown in Talble 1. There was variation in both the size of the YACs, and typing of markers (Table 2). Howerer. 
Table 1. YAC source and physical information

\begin{tabular}{|c|c|c|c|c|c|c|c|}
\hline \multirow[b]{2}{*}{$\mathrm{YAC}$} & \multirow[b]{2}{*}{ Souree } & \multicolumn{5}{|c|}{ Size $(\mathbf{M} \mathbf{b})$} & \multirow[b]{2}{*}{ Chromosome content } \\
\hline & & $G$ & $F$ & $B$ & $C^{\prime}$ & $B r$ & \\
\hline $846 c 4$ & $G$ & $1 \cdot 1$ & & $1 \cdot 4$ & 1.5 & $1 \cdot 6$ & \\
\hline $\mathrm{H} 109$ & ICRF & & & & & & \\
\hline $\mathrm{D} 213$ & ICRE & & & & & & \\
\hline $787 a 3$ & G & $1 \cdot 8$ & & 1.9 & $1 \cdot 0$ & & $9 \mathrm{q} 22,11,20$ \\
\hline $931 \mathrm{~d} 9$ & $\mathrm{G}$ & 0.9 & & 0.95 & 1.0 & $1 \cdot 1$ & $9 \mathrm{q} 22 . \mathrm{Xp}$ \\
\hline 21 b 8 & $G(F)$ & 1.5 & $1 \cdot 5$ & & & & \\
\hline $633 a 10$ & $\mathrm{G}$ & 1.5 & & $1 \cdot 0$ & & & $9 q 22,9 q 34,16 p, 13 q$ \\
\hline $928 \mathrm{e} 4$ & G. & $1 \cdot 4$ & & & & $1 \cdot 4$ & \\
\hline $946 \mathrm{h5}$ & G & $1 \cdot 1$ & & & & 1.0 & $9 \mathrm{q} 22$ \\
\hline $960 \mathrm{e} 1$ & $G$ & $1 \cdot 3$ & $0 \cdot 3$ & $0 \cdot 3$ & & & \\
\hline $932 \mathrm{~d} 12$ & $\mathrm{G}$ & $1 \cdot 0$ & & & & & \\
\hline $890 \mathrm{~g} 7$ & $\mathrm{G}$ & $1 \cdot 5$ & & & & $1 \cdot 4$ & $9 q 22$ \\
\hline $1 \mathrm{da} 10$ & ICI & & & & $0 \cdot 3$ & & $9 \mathrm{q}^{22}$ \\
\hline $2 \mathrm{ef} 8$ & ICI & & & & & & $9 \mathrm{q} 22$ \\
\hline $736 \mathrm{~b} 10$ & $\mathrm{G}$ & 0.8 & & & $0 \cdot 8$ & & $9 \mathrm{q} 22,1,19,5$ \\
\hline $754 c 7$ & $G$ & & & & 1.5 & & $9 \mathrm{~g} 22$ \\
\hline $8 \mathrm{ad} 8$ & ICI & & & $0 \cdot 65$ & 0.65 & & $9 q^{22}$ \\
\hline
\end{tabular}

YAC clones containing markers in the NBCCS region were obtained from Genethon (G), ICI, and ICRF libraries, were obtained by groups in Frederick (Dean), Cambridge (Barroso), Berlin (Morris), and Brisbane (Wicking). These YAC clones were sized, and typed for the markers indicated in Table 1. Markers are displayed in the order most supported by the typing data. Results are displayed as PCR positive (+), negative (-), or untested (N) (see Table 2).

the physical marker order supported by the YAC typing data was consistent between laboratories, and consistent with genetic linkage data, where these were available.

Uncertainty of ordering

Conflicting information was presented over the orientation and order of D9S134, D9S151 and D9S12. Data from fluorescent in situ hybridization on interphase cells, linkage data and the order from YACs favoured cen-D9S151-D9S12. Information from radiation hybrids (Obermayr et al.) favoured the order cen-D9S12-D9S151. Interphase FISH (Leversha et al.) places D9S134 distal to D9S12, but the CEPH map places D9S134 proximal to D9S12 (Attwood et al. 1994). Kwiatkowski et al. placed D9S151 proximal to D9S12 at odds of 1000:1.

Genetic interference

Linkage data was presented to support complete positive genetic interference in $9 \mathrm{q} 22$ as predicted by the male chiasmata maps of Lawrie and Hultén (First International Chromosome 9 Workshop). By direct counting of recombinant haplotypes between D9S12 and D9S53, the sex averaged distance between these markers was $10.5 \mathrm{cM}$ and the male to female ratio was $1: 1 \cdot 6$ (Farndon et al.). Apparently complete interference was also found on analysis of data from CEPH families (Kwiatkowski et al. 1993). Family studies using flanking markers for a disease in this region are therefore expected to give a high level of accuracy in predicting clinical status.

\section{Mouse homology}

The consensus view from data presented at the workshop was that the fusion between mouse chromosome 4 and 13 should be found between FACC and XPAC. Fleming et al. predicted that 
Table 2. NBCCS region YAC STS typing data

\begin{tabular}{|c|c|c|c|c|c|c|c|}
\hline YAC & $\begin{array}{c}\$ 151 \\
\text { FBCBr }\end{array}$ & $\begin{array}{l}S 12.1 \\
\text { FBCBr }\end{array}$ & $\begin{array}{l}\mathrm{S12.2} \\
\mathrm{FBCBr}\end{array}$ & $\begin{array}{l}\text { S197 } \\
\text { FBCbr }\end{array}$ & $\begin{array}{c}\$ 196 \\
\text { FBCBr }\end{array}$ & $\begin{array}{c}\$ 280 \\
\text { FBCBr }\end{array}$ & $\begin{array}{l}F A C \\
\text { FBC }\end{array}$ \\
\hline $846 c+1$ & $+--\lambda$ & +--- & $x-x y$ & $+++t$ & ++++ & --++ & $x-x-$ \\
\hline ICI $-\mathrm{H} 109$ & $-N X N$ & $+N N N$ & NXNN & $+N N$ & $-N N N$ & $-N N N$ & NXX \\
\hline ICI-D213 & $-N X N$ & $+N N N$ & NNNA & $+N N N$ & $-N N N$ & $-N N N$ & XNA \\
\hline $787 \mathrm{~A} 3$ & $--N$ & $+--N$ & $N+N N$ & $+++N$ & $--+N$ & $-+-N$ & $N-N N$ \\
\hline 931 D9 & $--N$ & $---\mathrm{N}$ & NNNN & ++++ & ++++ & ++++ & $-+N N$ \\
\hline $21 \mathrm{~B} 8$ & NNNN & $N N N$ & NNNN & $+N N-$ & $+\mathrm{NN}-$ & NNA- & $-N N-$ \\
\hline $633 \mathrm{~A} 10$ & $N--N$ & $N--N$ & $N-N N$ & $---N$ & $+++N$ & $-+-N$ & $-+N X$ \\
\hline $928 \mathrm{E} 4$ & $N N N N$ & $\mathrm{NNN}-$ & NNNN & $-N N N$ & $+N N+$ & $+\mathrm{NN}+$ & $+N N+$ \\
\hline $946 \mathrm{H} 5$ & $\mathrm{NNNN}$ & $\mathrm{NNN}-$ & NNNN & NNN & $-\mathrm{NN}+$ & $-N N+$ & $N N N N$ \\
\hline $960 \mathrm{E} 1$ & $N N N N$ & $N-N N$ & $N-N N$ & $--\mathrm{NN}$ & $--\mathrm{NN}$ & $++\mathrm{N} N$ & $++N N$ \\
\hline 932D12 & $N N N N$ & $N N N N$ & N NNN & NNNN & $+\mathrm{NNN}$ & $+\mathrm{NNN}$ & N N N N \\
\hline $890 \mathrm{G} 7$ & NNNN & NN NN & $\mathrm{NNNN}$ & NNNN & $-\mathrm{NNN}$ & $-\mathrm{NN}+$ & $-\mathrm{NNN}$ \\
\hline ICI-1DA10 & N NNN & $\mathrm{NNNN}$ & NNNN & NNNN & $\mathrm{NN}+\mathrm{N}$ & $\mathrm{NN}+\mathrm{N}$ & NNN \\
\hline ICI-2EF8 & NNNN & N N N N & NNNN & $N N-N$ & $N N-N$ & $N \mathrm{~N}+\mathrm{N}$ & NNNN \\
\hline $736 \mathrm{~B} 10$ & NNNN & N N N N & NNNN & $\mathrm{NN}-\mathrm{N}$ & $\mathrm{NN}-\mathrm{N}$ & $N N-N$ & NNN \\
\hline $754 \mathrm{C} 7$ & NNNN & N N N N & NNNN & $\mathrm{NN}-\mathrm{N}$ & $N N-N$ & $\mathrm{NN}-\mathrm{N}$ & NNNN \\
\hline ICI-8AD8 & $\mathrm{N} N \mathrm{NN}$ & $N--N$ & N N N N & $N--N$ & $N--N$ & $N--N$ & $N+N N$ \\
\hline & S287 & A2 & XPAC & $\mathbf{S} 180$ & $\mathrm{~S} 22$ & S6 & S176 \\
\hline YAC & $\mathrm{FBCBr}$ & FBCBr & FBCBr & $\mathrm{FBCBr}$ & FBCBr & FBCBr & FBCBr \\
\hline $846 c 4$ & ---- & $N N-N$ & $N--N$ & ---- & $\mathrm{NN}-\mathrm{N}$ & $\mathrm{N}--\mathrm{N}$ & $N--N$ \\
\hline ICI-H109 & $\mathrm{N} N \mathrm{NN}$ & N N N N & NNNN & $-\mathrm{NNN}$ & $\mathrm{NNNN}$ & $\mathrm{NNNN}$ & NNNN \\
\hline ICI-D213 & $\mathrm{NNNN}$ & $\mathrm{NN} \mathrm{NN}$ & NNNN & NNNN & $\mathrm{NNNN}$ & NNNN & NNNN \\
\hline $787 \mathrm{A3}$ & $N--N$ & $N N-N$ & $N--N$ & $---N$ & $\mathrm{NN}-\mathrm{N}$ & $N--N$ & $N--N$ \\
\hline 931D9 & --- & $N \mathrm{~N}-\mathrm{N}$ & $N--N$ & $---N$ & $\mathrm{NN}-\mathrm{N}$ & $N--N$ & $N--N$ \\
\hline $21 \mathrm{~B} 8$ & $+\mathrm{NN}-$ & N N N N & $+\mathrm{NNN}$ & $+\mathrm{NN}-$ & NNNN & $\mathrm{NNNN}$ & N N N N \\
\hline $633 \mathrm{A1} 10$ & $+--N$ & $\mathrm{~N} N-\mathrm{N}$ & $---N$ & $N--N$ & $-N-N$ & $---N$ & $\mathrm{~N}--\mathrm{N}$ \\
\hline $928 \mathrm{E} 4$ & $-\mathrm{NN}+$ & N N N N & $-N N N$ & N N NN & $\mathrm{NNNN}$ & $-\mathrm{NNN}$ & $\mathrm{NNNN}$ \\
\hline $946 \mathrm{H} 5$ & $+\mathbf{N N}+$ & $\mathrm{NNNN}$ & $-\mathrm{N} N \mathrm{~N}$ & $\mathrm{NNN}-$ & $-\mathrm{NNN}$ & $-N N N$ & $\mathrm{NNNN}$ \\
\hline $960 \mathrm{E} 1$ & $++\mathrm{NN}$ & N N N N & $-+\mathrm{NN}$ & $\mathrm{N}-\mathrm{NN}$ & N N N N & $--N N$ & $N-N N$ \\
\hline 932D12 & $+\mathrm{NNN}$ & N N N N & $-\mathrm{NNN}$ & N N N N & N N N N & $-\mathrm{NNN}$ & N N N N \\
\hline $890 \mathrm{G} 7$ & $-\mathrm{NN}+$ & N N N N & $+\mathrm{NNN}$ & $+\mathrm{NN}+$ & $\mathrm{NNNN}$ & $\mathrm{NNNN}$ & NNN \\
\hline ICI-1DA10 & $\mathrm{NN}+\mathrm{N}$ & $N N+N$ & $\mathrm{NN}-\mathrm{N}$ & $\mathrm{NN}-\mathrm{N}$ & $\mathrm{N} N \mathrm{~N}$ & N N N N & $\mathrm{NNNN}$ \\
\hline ICI-2EF8 & $\mathrm{N} N+\mathrm{N}$ & $N N+N$ & $\mathrm{NN}-\mathrm{N}$ & $N N-N$ & $N N N N$ & NN NN & $N N N N$ \\
\hline $736 \mathrm{~B} 10$ & $\mathrm{~N} N-\mathrm{N}$ & $\mathrm{NN}+\mathrm{N}$ & $N N+N$ & $\mathrm{~N} N-\mathrm{N}$ & $\mathrm{NN}-\mathrm{N}$ & $\mathrm{NN}-\mathrm{N}$ & NNNN \\
\hline $754 \mathrm{C} 7$ & $\mathrm{~N} N-\mathrm{N}$ & $N N+N$ & $\mathrm{NN}+\mathrm{N}$ & $\mathrm{NN}+\mathrm{N}$ & $\mathrm{NN}+\mathrm{N}$ & $\mathbf{N N}-\mathbf{N}$ & $N N N N$ \\
\hline ICI-8AD8 & $\mathbf{N}+-\mathbf{N}$ & $\mathrm{NN}+\mathrm{N}$ & $\mathrm{N}++\mathrm{N}$ & $\mathrm{N}++\mathrm{N}$ & $\mathrm{NN}+\mathrm{N}$ & $\mathbf{N}++\mathbf{N}$ & $N+-N$ \\
\hline
\end{tabular}

Key: F, Frederick; B, Berlin; C, Cambridge, UK; Br, Brisbane. +, PCR positive; -, PCR negative; $\mathrm{N}$, untested.

a human homologue to a mouse autosomal recessive deafiness gene should be located in the interval between ALAD and HXB. This on FISH interphase is a distance of about 1.7 megabases. This is certainly an area which should be included in studies of deafness by homozygosity mapping.

$$
9 q 34-q \text { ter }
$$

\section{Newly mapped genes}

Several genes have been given more refined map positions since the last meeting. These include COL5A1 (Northrup et al., Zahn et al.), AK1, SPTAN1, CEL, PAEP, TAN1 (now designated NOTOH1) (Woodward et al., Leversha et al.) and GRIN1 (Brett et al. 1994 (see Fig. 6)). A new disease gene, ORW (Haemorrhagic telangiectasia, Osler Rendu Weber 


\begin{tabular}{|c|c|c|c|c|c|}
\hline \multirow{3}{*}{ NPS } & \multirow{2}{*}{$\mid \begin{array}{l}\text { Marker } \\
\text { AK1y }\end{array}$} & \multirow{2}{*}{$\mathrm{cM}$} & $\mathrm{Mb}$ (FISH) & \multirow[t]{2}{*}{$\mathrm{Mb}(\mathrm{PFG})$} & \multirow[t]{2}{*}{$\mathrm{Mb}$ (contig) } \\
\hline & & & 1.4 & & \\
\hline & SPTAN1 & 1 & & & \\
\hline \multirow[b]{2}{*}{ D9S315 } & D9S61 & - & 0.4 & & \\
\hline & D $9565 / S 115$ & 5 & 0.95 & & \\
\hline \multirow{3}{*}{ D9S159 } & $n 9562 y$ & 1 & 0.30 & & \\
\hline & D9502y & 0 & 0.425 & & \\
\hline & D9S63y & & & & \\
\hline \multirow{3}{*}{$\begin{array}{l}\text { D9S313 } \\
\text { D9S179 } \\
\text { DYT1 }\end{array}$} & & 1 & 0.725 & & \\
\hline & ASSy & & & & \\
\hline & ABLy & 0 & 0.30 & - & \\
\hline \multirow{2}{*}{$\begin{array}{l}\text { Can } \\
\text { D9S46E }\end{array}$} & D9s113/S148v & 1 & 090 & & \\
\hline & 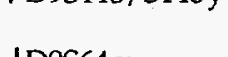 & 1 & 0.0 & $<2.0$ & \\
\hline \multirow{6}{*}{$\begin{array}{l}\text { CEL } \\
\text { Surf1-6 }\end{array}$} & D9564 y & 1 & - & & \\
\hline & D9S125y & 1 & 1.4 & $<0.65$ & \\
\hline & D9S149y & & & - & \\
\hline & $A B O y$ & & - & & \\
\hline & D9S150 & 0 & 0.65 & $<2.5$ & - \\
\hline & DRHy & 0.3 & & & \\
\hline \multirow{3}{*}{$\begin{array}{l}\text { TSC1 } \\
\text { D9S164 }\end{array}$} & Dotiy & 0.3 & & & \\
\hline & D9S122y & 0 & 030 & & 0.2 \\
\hline & D9S10y & & & & \\
\hline \multirow[t]{2}{*}{ VAV2 } & & 0 & & & \\
\hline & $0>000 y$ & 2 & . & & - \\
\hline \multirow{5}{*}{$\begin{array}{l}\text { RXRA } \\
\text { COL5A1 } \\
\text { D9S740 }\end{array}$} & D9S114y & 3 & & & \\
\hline & lD9S298y & - & & & \\
\hline & & & 1.4 & & \\
\hline & Dys23 & 4 & & & \\
\hline & D9S14 & & & & \\
\hline $\begin{array}{l}\text { PAEP } \\
\text { TAN1 }\end{array}$ & D9S67 y & - & - & & \\
\hline \multirow[t]{2}{*}{ GRIN1 } & D9S158y & 5 & & & \\
\hline & D9S11 & - & & & \\
\hline D9: & & & & & \\
\hline
\end{tabular}

Fig. 6. High resolution map of 9q34. Distances are not drawn to scale. The cM and Mb distanir. between markers are shown. Dashes indicate the endpoints of measured distance when the miarkm.r. are not adjacent in the listing from top to bottom. $y$ indicates that a yac clone has been iclentitied 
synarome), has been mapped between D9S60 and D9S159 by linkage analysis (Marchuk et al.). There is some evidence for existence of a new gene with homology to the VAV oncogene rery close to D9S66 (Smith et al., Woodward et al.).

Genetic mapping

Several polymorphisms received refined positions, including D9S298, D9S158 and D9S207. The primary genetic map has been modified slightly, with the replacement of the VNTR markers D9S17 and D9S7 with D9S158. The data for D9S158 and D9S11 have been extensively checked and results in a shrinkage in sex-averaged map distance of $6 \mathrm{cM}$; the distance from $\mathrm{S} 67$ to the most distal marker D9S11 now estimated as $5.5 \mathrm{cM}$ in females and $12.2 \mathrm{cM}$ in males (Jeremiah et al.). Two groups described polymorphisms of COL5A1, placing the gene distal to D9S114 (Northrup et al., Zahn et al.).

\section{Physical mapping}

Two regions have been subject to extensive physical mapping (see Fig. 6). The region between GSN-D9S61 has been mapped by interphase FISH, ordering the markers GSN-D9S60-AK1SPTAN1-D9S61. Leversha et al. have generated an extended interphase FISH map from GSN to DBH, spanning an estimated $14 \mathrm{Mb}$. The second region is ABO to D9S67. Cosmid, YAC and P1 contigs exist for D9S150-DBH-D9S122-D9S10-D9S66, and these markers span approximately $350 \mathrm{~kb}$. Cosmid or YAC contigs exist around many genes and markers in a more extended region (Janssen et al., Jobert et al., Kumar et al., Hornigold et al., Murrell et al., Zhou et al.) some of which are described in detail (Hornigold et al.) but there are several gaps in the region proximal to ABO. A gap also exists between D9S66 and D9S114, but a Y AC contig exists spanning D9S114-D9S23-D9S14-D9S67. A pulsed field map of genomic DNA extending from ABL to D9S114 was presented (Henske \& Kwiatkowski) with these markers lying between $4 \cdot 5$ and $6.7 \mathrm{Mb}$ apart.

\section{New unresolved difficulties}

Three major inconsistencies have arisen in this region. D9S179, D9S125 and D9S164 span a minimum of $4 \mathrm{cM}$ by linkage analysis covering an estimated $3 \mathrm{Mb}$. However, all three markers have been found within a single $200 \mathrm{~kb}$ YAC (Murrell pers. comm.). The second controversy surrounds the order of D9S67 and D9S14. Genetic mapping data suggest that D9S14 is distal (Attwood et al. \& global group) while YAC maps suggest the reverse. Finally, D9S298 maps between D9S114 and D9S67 by genetic mapping (Jeremiah et al., Attwood et al. 1993) and physical mapping confirms that it is distal to D9S114 (Woodward et al., Nahmias et al.) but is not found within the YAC-contig which spans this region.

\section{Location of bladder and ovarian carcinoma genes}

$\mathrm{LOH}$ studies of bladder tumours now define two regions of deletion on chromosome 9 which may be deleted independently or concurrently in individual bladder tumours (Keen \& Knowles). Homozygous deletions in the region 9p21-22 have been found and a region of deletion between D9S162 and D9S171 has been delineated (Cairns et al., Devlin \& Knowles). The common region on $9 q$ is large (D9S15-D9S60). This may suggest that more than one 

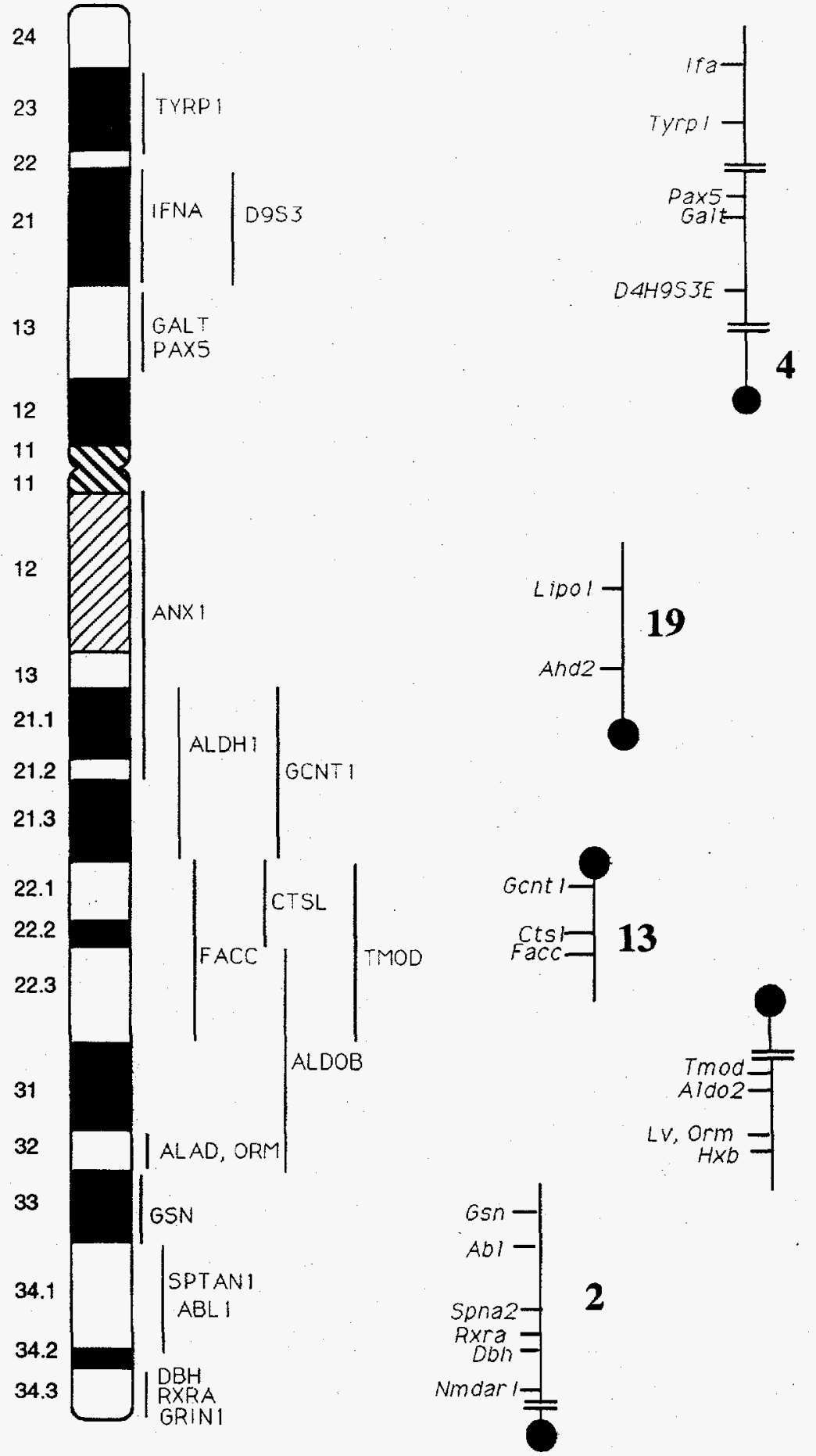

Fig. 7. Human chromosome 9 aligned with the homologous regions of mouse chromosomes $2,4,13$ and 19. Not all markers from this study are shown for simplicity. The centromere of the mouse chromosomes is shown by a filled circle. Chromosome 4 is shown twice to make comparison easier. Ahd2, Lipo1, Lv, Aldo2, Spna2 and Nmdar1 are the mouse homologues of ALDH1, ANX1, ALAD, ALDOB, SPTAN1 and GRIN1 respectively. 
relevant suppressor locus for bladder cancer exists on $9 q$. LOH studies of $9 q$ in ovarian tumours (Osborne et al.) define a common region of deletion within that defined for bladder tumours between D9S160 and D9S115.

COMPARATIVE MAPPING RELEVANT TO HUMAN CHROMOSOME 9

The report on comparative mapping in the mouse was prepared by Alison Pilz and is summarized in Fig. 7. A summary of data from many other species, the unpublished data of J. Graves and M. Wakefield, was generously provided to the workshop and is shown in Fig. 8. Any queries about the data in Fig. 8 should go to the contributors at gemap@genome. latrobe.edu.au.

A high resolution genetic linkage map of the mouse facilitates the establishment of gene order on human chromosomes. Comparative mapping enables the identification of mouse mutations which are potential models of human genetic disease.

Genes mapping to human chromosome 9 have homologues which map to four different mouse chromosomes; namely mouse chromosomes $2,4,13$ and 19. The homology group with mouse chromosome 13 (MMU13) has been defined since last year's report. The distal portion of the long arm of human chromosome 9 (HSA9) shows homology with mouse chromosomes 2 and 4 . Loci in the distal region of $9 \mathrm{q} 34$ (e.g. ABL and C5) have homologues on proximal MMU2, and genes mapping more proximally (e.g. ORM and ALAD) have homologues on MMU4. The homology on mouse chromosome 4 (MMU4) is in three segments - two regions of synteny with human chromosome $9 \mathrm{p}$ are separated physically by a region syntenic with $9 q$. Genes mapping to HSA 9q21-q22 map to mouse chromosome 13 whilst genes which map to HSA9q12-q21 map to mouse chromosome 19. Presumably therefore an evolutionary breakpoint has occurred in HSA9q21. The mouse homologue of Gorlin's syndrome would be predicted to map on MMU13. Figure 7 shows the conserved mouse syntenies aligned with the chromosome 9 map.

A number of predictions for gene order in human may be made based on a comparison of the human and mouse maps. Genes which have not been genetically separated in reasonably large crosses in the mouse would be predicted to map close to each other in human. When comparing the gene order for MMU2 to the consensus gene order for HSA9q34 (taken from Kwiatkowski et al. 1993) the conserved segment appears to be inverted in one species compared to the other. Within the segment gene order is the same except for two loci, Rxra (RXRA) and SpnaZ (SPTAN1). In mouse Spna2 maps proximal to $A b l$, and Rxra maps distal to $D b h$. These differences between the mouse and human gene maps probably indicate real evolutionary differences, although the possibility of errors in mapping cannot be excluded. For the mouse, there is a considerable degree of confidence in the proposed gene order of $S p n a 2$ in relation to $A b l$ and $H c$ as the order has been derived from four independent crosses in which all three loci have been mapped. If both maps are an accurate reflection of gene order in the two species, then the simplest explanation of the evolutionary change would be that there have been two small inversions (in mouse with respect to human or vice versa) within this syntenic group, one involving RXRA and DBH, and the other involving SPTAN1 and ABL. Further studies are required to determine whether the apparent difference in gene order between mouse and human represents a true evolutionary divergence.

Lawrie and Hultén investigated whether the genetic length of segments is conserved between 

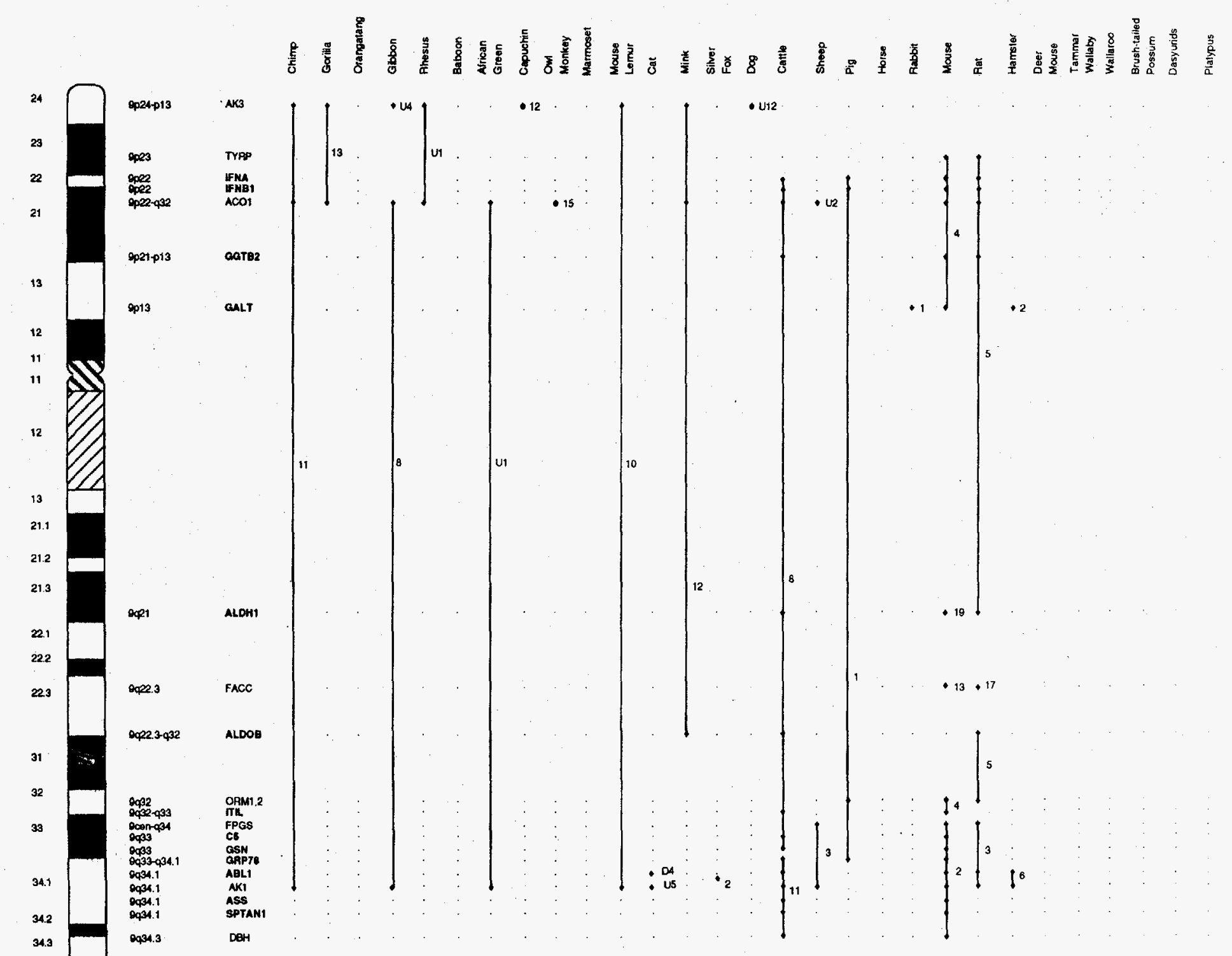

Fig. 8. Comparisons of gene locations in other mammals, of loci which map to human chromosome 9. Markers are plotted with reference to their physical location on the human chromosome, and have been induded only if mapped in species other than human and mouse. (Unpublished data of Graves and Wakefield.) 
Table 3. House mutants whose human homologues would be expected to map to human chromosome 9

\begin{tabular}{|c|c|c|c|c|}
\hline $\begin{array}{l}\text { Mouse } \\
\text { chrom. }\end{array}$ & $\begin{array}{c}\text { Gene } \\
\text { symbol }\end{array}$ & Mutation & Phenotype & $\begin{array}{c}\text { Predicted HSA9 } \\
\text { location }\end{array}$ \\
\hline MIML2 & $s d$ & Danforth's short tail & Kidney/notochord development & $9 q 33-q 34$ \\
\hline MMU2 & $s t b$ & stubby & Achondroplasia & $9 q 33-q 34$ \\
\hline MML2 2 & lh & lethargic & Neurological/immunological & $9 \mathrm{q} 33-\mathrm{q} 34$ \\
\hline MML 2 & us & urogenital syndrome & Skeletal/urogenital abnormalities & $9 \mathrm{q} 34.1-\mathrm{q} 34$ \\
\hline MMC4 4 & an & Hertwig's anaemia. & Haematological & $9 p / 9 q$ \\
\hline MMU4 & $v c$ & vacillans & Neurological & $9 \mathrm{p} / 9 \mathrm{q}$ \\
\hline MMU4 & $c y$ & crinkly tail & Tail & $9 \mathrm{p}$ \\
\hline MMU4 & dep & depilated & Hair & $9 \mathrm{p}$ \\
\hline MMU4 & $P t$ & Pintail & Tail & $9 \mathrm{p}$ \\
\hline MMU4 & $w i$ & whirler & Deafness/inner ear & $9 q 32-q 34$ \\
\hline MMU13 & $s d y$ & sandy & Coat & $9 \mathrm{q} 21-\mathrm{q} 22$ \\
\hline MMU13 & $m u$ & muted & Balance/ear & $9 q 21-q^{2} 2$ \\
\hline MMU13 & $j d$ & juvenile depilation & Hair & $9 q^{21}-q^{2} 2$ \\
\hline MMU13 & $d p y$ & dumpy & Skeletal & $9 q^{21-q} 22$ \\
\hline MMU13 & $f$ & flexed-tail & Tail & $9 q 21-q 22$ \\
\hline MMU19 & $b m$ & brachymorphic & Achondroplasia & $9 \mathrm{q} 12-\mathrm{q} 21$ \\
\hline
\end{tabular}

species. They compared male chiasma maps of the relevant segments of MMU2 and MMU4 and HSA9, and concluded that there was no apparent conservation of meiotic recombination for the segments.

The comparative mapping data also predict the occurrence of human homologues of several mouse mutations the phenotypes of which are listed in Table 3 (data taken from mouse chromosome committee reports in Mammalian Genome Special Issue 4, 1993, and Fleming et al., this meeting).

\section{RESOURCES}

\section{Physical resources}

Cellular resources on chromosome 9 include a number of lymphoblastoid lines with balanced translocations, described in the report of the First International Workshop on chromosome 9 and which have been useful to several workers (e.g. Woodward et al.). A new compilation of constitutive rearrangements involving chromosome 9 was presented at this meeting (Edwards \& Mercer, see abstract for details). A hybrid containing a t6/9 (9pter-q22.3:6pter-p23) as its only human chromosome apart from a small part of the $\mathrm{X}$ has recently been generated by $\mathrm{Dr}$ Mike Dixon (Department of Cell and Structural Biology, University of Manchester, UK. fax $44612753915)$ and anyone interested should contact him.

Apart from previously described irradiation hybrids (Nahmias et al.; Britt et al.) five other sets of radiation hybrids were presented at this meeting. Radiation hybrids for chromosome ! now include four sets of hybrids made from an original hybrid containing a whole chromoseme. 9, three of these characterized mostly for $9 \mathrm{p}$ markers (Britt et al., Kaur \& Athwal and personal communication from Nigel Spurr), and one useful for $9 q$ (Kaur \& Athwal). Three groups has * used a hybrid containing $9 q$ as its only human component to generate radiation hybrids. $t \cdots$. concentrating on 9q22-q31 (Obermayr et al., Wicking et al.) and one on 9q34 (Nahmias el al) These hybrids are mostly available to others on a collaborative basis although this is sometime- 
Table 4. Human chromosome 9 loci containing microsatellite repeats

(a) Estimates of heterozygosity are determined from four CEPH families. (b) The number of alleles observed in eight unrelated individuals

Loci assigned to chromosome 9 by two-point linkage analysis with Genethon microsatellite markers

\begin{tabular}{|c|c|c|c|c|}
\hline Name & GDB\# & GenBank\# & Het(a) & Motif \\
\hline $\mathrm{LT} 1220$ & $\operatorname{D9S762}$ & L31161 & 0.50 & GATA \\
\hline UT1228 & D9S249 & L15543 & 0.50 & GATA \\
\hline ET1231 & D9S250 & L 18540 & 0.50 & $\mathrm{GATA} / \mathrm{GA} / \mathrm{AAAG}$ \\
\hline $\mathrm{CT} 1277$ & D9S763 & L17788 & $0 \cdot 50$ & $\mathrm{GATA} / \mathrm{CA}$ \\
\hline UT1416 & D9S764 & $\mathrm{L} 17814$ & $1 \cdot 00$ & $\mathrm{AAAG}$ \\
\hline $\mathrm{UT} 1531$ & D9S765 & L30884 & 0.57 & $\mathrm{GA} / \mathrm{GGGA}$ \\
\hline UT1892 & $\operatorname{D9S766}$ & L17918 & $0 \cdot 83$ & GGAA/GA \\
\hline $\mathrm{UT} 2100$ & D9\$25.1 & $\mathrm{L} 18726$ & 0.50 & GATA \\
\hline UT2103 & $\mathrm{D} 9 \mathrm{~S} 252$ & L17974 & 0.88 & GATA \\
\hline UT2163 & $\operatorname{DgS767}$ & L17984 & $0 \cdot 33$ & $\mathrm{AGC}$ \\
\hline $\mathrm{UT} 2372$ & D9S255 & L18736 & $0 \cdot 38$ & $\mathrm{AAAG} / \mathrm{GGAA}$ \\
\hline UT2399 & D9S253 & L18027 & 0.75 & GATA \\
\hline $\mathrm{UT} 2420$ & D9S254 & L18050 & 0.62 & GATA \\
\hline UT457. & D9S225 & L18282 & 0.50 & $\mathrm{CA}$ \\
\hline UT458 & D9S226 & L18283 & 0.62 & AAAG \\
\hline UT5024 & D9S245 & L18515 & 0.50 & GATA \\
\hline UT5110 & D9S761 & L17697 & 0.62 & AAAG \\
\hline UT5132 & D9S248 & L16438 & 0.75 & AAAG \\
\hline UT535 & D95755 & L31701 & 0.50 & AAAT \\
\hline UT5494 & $\operatorname{D9S768}$ & L18114 & $0 \cdot 67$ & GATA \\
\hline UT6023 & $\operatorname{D9S769}$ & L30683 & $0 \cdot 86$ & AAAG \\
\hline UT6068 & $\operatorname{D9S752}$ & L30703 & 0.88 & GATA \\
\hline UT6090 & D9S737 & L18104 & 0.88 & AAAG \\
\hline UT6185 & $\operatorname{DgS771}$ & L30755 & $0 \cdot 38$ & AAAG \\
\hline UT6211 & $\operatorname{DgS770}$ & L30747 & 1.00 & AAAG/GA \\
\hline UT6405 & $\operatorname{D9S773}$ & L30619 & 0.75 & $\mathrm{AAT}$ \\
\hline UT6556 & D9S772 & L30569 & 1.00 & GGAA/GA \\
\hline UT683 & D9S229 & L18370 & $0 \cdot 83$ & AAAG/GGAA \\
\hline UT685 & $\mathrm{D} 9 \mathrm{~S} 230$ & L16312 & 0.67 & $\mathrm{CA}$ \\
\hline UT724 & D9S232 & L18384 & 0.62 & $\mathrm{AAAG}$ \\
\hline UT726 & D9S234 & L16322 & 1.00 & AAAG \\
\hline UT727 & D9S236 & L18386 & $0 \cdot 62$ & $\mathrm{CA}$ \\
\hline UT739 & $\operatorname{DgS} 237$ & L16324 & 0.62 & AAAG/GGAA \\
\hline UT7422 & $\operatorname{DgS774}$ & L30444 & $0 \cdot 88$ & GATA \\
\hline UT7622. & D9S775 & L30528 & $0 \cdot 75$ & GATA \\
\hline UT764 & D9S757 & L31180 & $0 \cdot 67$ & AAAG \\
\hline UT7655 & D9S776 & L30291 & 0.83 & GATA \\
\hline UT7939 & D9S777 & L30395 & 0.86 & AAAG \\
\hline UT7968 & D9S778 & $\mathrm{L} 30161$ & 088 & $\mathrm{AAAG} / \mathrm{GA}$ \\
\hline UT801 & D9S238 & L18422 & 0.83 & AAAT \\
\hline UT8063 & D9S753 & L30185 & 1.00 & AAAG \\
\hline UT8065 & $\operatorname{DgS779}$ & L30188 & 0.50 & AAAG \\
\hline UT808 & $\mathrm{ND}$ & L16335 & 0.33 & AAAT \\
\hline UT840 & D9S758 & L31235 & 0.75 & AAAG/AG \\
\hline UT844 & D9S750 & L31239 & $0-88$ & GA/AAAG \\
\hline UT873 & D9S759 & L31258 & $0 \cdot 62$ & GGAA/GAAA \\
\hline UT913 & D9S241 & L.18466 & $0 \cdot 75$ & AAAG \\
\hline UT914 & D9S242 & L18467 & $0 \cdot 88$ & AAAG \\
\hline UT915 & $\mathrm{D} 9 \mathrm{~S} 243$ & L18468 & $0 \cdot 88$ & GGAA/AAAG \\
\hline UT917. & D9S244 & L18469 & 1.00 & $A A A G$ \\
\hline
\end{tabular}


Table 4 (cont.)

Assigned to chromosome 9 by results of $\mathbf{P C R}$-amplification of Coriel somatic cell hybrid mapping panel

$\begin{array}{rcccl}\text { Tame } & \text { GDB\# } & \text { GenBank\# } & \text { \# alleles (b) } & \text { Motif } \\ \text { UT536 } & \text { D9S227 } & \text { L18321 } & 1 & \text { CA } \\ \text { ET537 } & \text { D9S228 } & \text { L18322 } & 3 & \text { CA } \\ \text { LT684 } & \text { D9S756 } & \text { L30078 } & 6 & \text { AAAG } \\ \text { UT725 } & \text { D9S233 } & \text { L18385 } & 2 & \text { AAAG } \\ \text { UT728 } & \text { D9S236 } & \text { L18387 } & 1 & \text { CA } \\ \text { CT911 } & \text { D9S239 } & \text { L18464 } & 1 & \text { AAAG } \\ \text { UT912 } & \text { D9S240 } & \text { L18465 } & 1 & \text { AAAT } \\ \text { UT916 } & \text { D9S760 } & \text { L31287 } & 2 & \text { AAAG }\end{array}$

limited by the tendency of these hybrids to lose fragments when regrown. It is hoped to put more details of the hybrids on the chromosome 9 file-server.

Cosmids

At least eight groups present at the meeting had been working with the Laurence Livermore chromosome 9 flow sorted gridded cosmid library made by Pieter de Jong, and all reported it to be of high quality and extremely useful. The library has been distributed in two formats (300 normal density microtitre plates or 75 high density plates) and Dr de Jong made a request that publication should identify clones using the 300 plate nomenclature (see abstract by Hornigold et al. for contigs with clones identified in this way). The only gap identified so far in this library is that it appears to lack clones for the ABO blood group in 9 q34.1.

Another cosmid resource which has been described in the past year is a flow sorted chromosome 9 library produced in Dr Nakamura's lab and for which 203 cosmids have already been mapped by FISH (Takahashi et al. 1994). The distribution of these cosmids again shows $9 q 34$ to be over represented. Dr Nakamura has already shared some of these cosmids with other workers.

$Y A C s$

Eleven abstracts at this meeting described work with YACs, but this has in general been concentrated on a limited number of areas, in particular 9p21, 9q11-q21; q22.3-31 (four groups) and $q 34$ (five groups). The most useful sharing of information came from 9q22.3-4;31 and the results of all groups working in this region are shown in the appropriate regional report. In 9q34 two groups reported a YAC for ABO, (Jobert et al., Zhou et al. presumably the same clone) from one of the CEPH libraries, suggesting that this region is clonable in YACs if not in cosmids. Jill Murrell reported that the chromosome 9 YAC library made by Mary $k$ McCormack is now available on a collaborative basis.

The greatest number of YACs added to chromosome 9 in the past year is of course from Genethon. Information on these YACs can be obtained from GDB or the Genethon file server and the YACs themselves are obtainable from the ICRF. It was agreed that notification "If YACs found to be chimeric or mapping completely to an unexpected chromosome, would the it useful addition to the information on the chromosome 9 fileserver. Any information on thi.. topic should go to John Attwood. 


\section{Other cloned resources}

Ioannou. Kroisel et al. described a micro-dissection library from 9q12-21 of 50000 clones in Bluescript. Ioannou P. de Jong et al. described a currently a vailable genomic PI library which has already been used successfully on chromosome 9 (Kumar et al., Zhou et al., Ioannou. Frenger et al.). This library has four fold redundancy and exists as 312 high density ( 384 well) microtitre plates. A new generation of $\mathrm{PAC}$ vectors especially appropriate for expression studies in mammalian cells locus was also described.

In GDB 109 entries are expressed sequences on chromosome 9 (other than those designated as genes): these include 70 trapped exons some of which have regional mapping information (Church et al. 1993).

\section{Polymorphisms}

Six new tetranucleotide repeats on chromosome 9 were reported at this meeting; D9S739 and D9S740 (J. Armour) and D9S745, D9S746, D9S747 and D9S748 (Zahn et al.). Since the primers for these and for all the new Genethon and CHLC markers are in GDB they are not repeated here. Table 4 shows details of 59 new polymorphisms on chromosome 9 mostly tetranucleotide repeats, described by the Utah Genome Center, Genetic Marker and Mapping group, which includes Linda Ballard, Hans Albertsen, Paige Bradley, Steve Gerken, Pilar Holik, Norisada Matsnami, Elisabeth Lawrence, Robert Melis, Mary Moore, Shanon Odelberg, Margaret Robertson, Rosemarie Plaetke, Xuyn Zhao and Ray White. For 45 of these markers pairwise lodscores indicating a close Genethon marker on chromosome 9 are shown in Table 5. Most of the other polymorphisms were assigned to chromosome 9 by somatic cell hybrids. The primer sequences for all these polymorphisms are in GDB.

\section{Informatics}

In addition to the SIGMA program being used to construct the map, other programs demonstrated at the Workshop included ldb (Collins et al.) and a comparative mapping database (Edwards). Jamie Cuticchia demonstrated various new features of GDB, especially a user-friendly version accessible via any Mac on a network. An internet connection was established through a modem connection to the Cambridge University Computer Centre and quite a number of participants learned something of the art of accessing an anonymous fileserver and downloading files either from Genethon, Chromosome 9 at UCL or CHLC. The vast majority of participants now have email addresses and this should really improve communication in the future. Information about chromosome 9 , including the current SIGMA map and database, the ldb map and database, this report plus the abstracts and participant list, the HGM93 report and EST reports for chromosome 9 are currently available by anonymous FTP from ftp.gene.ucl.ac.uk (128.40.82.1), in the sub-directory /pub/c9workshop/1994. Wherever possible, plain ASCII text files have been made available as well as PostScript versions for high-quality printout. Hopefully, in the future, details of YAC and FISH results and radiation hybrids on Chromosome 9 will also be available by the same means. Everyone on the Chromosome 9 electronic mail list receives information about future meetings and is also notified when new information is placed on the FTP server. Anyone wishing to join the electronic mail list should contact John Attwood (john@mrc-hbgu.ucl.ac.uk). 
Table 5. Pairwise analysis of linkage between Ctah markers and Genethon markers. lod score $\left(Z_{\max }\right)$ at recombination fraction (theta)

\begin{tabular}{|c|c|c|c|}
\hline $\begin{array}{l}\text { Ctah } \\
\text { marker }\end{array}$ & $\begin{array}{l}\text { Genethon } \\
\text { marker }\end{array}$ & $Z_{\max }$ & Theta \\
\hline D9S762 & D9S15̃ & $10 \cdot 6$ & $0 \cdot 024$ \\
\hline D9S249 & D9S152 & $5 \cdot 4$ & $0 \cdot 097$ \\
\hline D9S250 & D9S170 & $7 \cdot 7$ & 0.031 \\
\hline D9S763 & D9S176 & $5 \cdot 4$ & 0.001 \\
\hline D9S764 & D9S152 & $12 \cdot 0$ & 0.038 \\
\hline D9S765 & D9S176 & $8 \cdot 5$ & $0 \cdot 024$ \\
\hline D9S766 & D9S159 & $14 \cdot 4$ & 0.001 \\
\hline D9S251 & D9S161 & $4 \cdot 6$ & $0 \cdot 048$ \\
\hline D9S252 & D9S152 & $8 \cdot 4$ & 0.082 \\
\hline \multirow[t]{2}{*}{ D9S767 } & D9S176/ & 63 & 0.001 \\
\hline & $\begin{array}{l}\text { D9S174/ } \\
\text { D9S155 }\end{array}$ & & \\
\hline D9S255 & D9S196 & 7.8 & 0.001 \\
\hline D9S253 & D9S196 & $7 \cdot 8$ & 0.001 \\
\hline D9S254 & D9S157 & $12 \cdot 0$ & $0 \cdot 020$ \\
\hline D9S225 & D9S165 & $6 \cdot 3$ & 0.001 \\
\hline D9S226 & D9S175 & $12 \cdot 3$ & $0 \cdot 001$ \\
\hline D9S245 & D9S153 & $6 \cdot 6$ & 0.001 \\
\hline D9S761 & D9S175 & $8 \cdot 8$ & $0 \cdot 095$ \\
\hline D9S248 & D9S175 & $10 \cdot 9$ & .0 .057 \\
\hline D9S755 & D9S167 & $6 \cdot 0$ & 0.001 \\
\hline D9S768 & D9S153 & $9 \cdot 0$ & 0.001 \\
\hline D9S769 & D9S175 & $15 \cdot 9$ & 0.001 \\
\hline D9S752 & D9S159 & $17 \cdot 0$ & 0.015 \\
\hline D9S737 & D9S170 & 19.5 & 0.001 \\
\hline D9S771 & D9S196 & 7.9 & 0.001 \\
\hline D9S770 & D9S157 & $6 \cdot 4$ & 0.086 \\
\hline D9S773 & D9S175 & $10 \cdot 2$ & 0.080 \\
\hline D9S772 & D9S166 & 4.8 & 0.001 \\
\hline D9S229 & D9S166 & 6.9 & 0.001 \\
\hline D9S230 & D9S178 & $6 \cdot 3$ & 0.001 \\
\hline D9S232 & D9S168 & 7.7 & 0.073 \\
\hline D9S234 & D9S175 & $9 \cdot 3$ & 0.068 \\
\hline D9S236 & D9S157 & $12 \cdot 6$ & 0.001 \\
\hline D9S237 & D9S175 & $12 \cdot 6$ & 0.001 \\
\hline D9S774 & D9S172 & $11 \cdot 4$ & 0.001 \\
\hline D9S775 & D9S168 & $15 \cdot 3$ & $0 \cdot 001$ \\
\hline D9S757 & D9S176 & $22 \cdot 3$ & 0.001 \\
\hline D9S776 & D9S167 & $11 \cdot 7$ & 0.039 \\
\hline D9S777 & D9S152 & 6.4 & $0 \cdot 159$ \\
\hline D9S778 & D9S177 & $12 \cdot 5$ & $0 \cdot 038$ \\
\hline D9S238 & D9S175 & $12 \cdot 0$ & 0.039 \\
\hline D9S753 & D9S196 & $14 \cdot 4$ & 0.001 \\
\hline D9S779 & D9S174 & $9 \cdot 6$ & 0.001 \\
\hline UT808 & D9S167 & $4 \cdot 6$ & 0.048 \\
\hline D9S758 & D9S 166 & $9 \cdot 6$ & 0.001 \\
\hline D9S750 & D9S 176 & $22 \cdot 3$ & 0.001 \\
\hline D9S759 & D9S168 & $10 \cdot 8$ & 0.001 \\
\hline D9S241 & D9S177 & $12 \cdot 9$ & 0.020 \\
\hline D9S242 & D9S177 & $14 \cdot 8$ & 0.032 \\
\hline D9S243 & D9S177 & 18.5 & $0 \cdot 014$ \\
\hline D9S244 & D9S153 & $14 \cdot 0$ & 0.033 \\
\hline
\end{tabular}


Anyone with data they wish to share with the Chromosome 9 Community ean up-load it to the anonymous FTP server to the sub-directory / pub/incoming (please also send electronic mail to John Attwood explaining what you have up-loaded).

It is hoped that the SIGIIA map will be modified on an ongoing basis, and that updated versions will be made available on the FTP server throughout the year. This of course relies on the Chromosome 9 Community checking the existing map and contributing new map information to the general pool. It should be noted that it is not yet simple to merge SIGMIA maps. Thus, although it is possible to download the SIGMA map database file, view and edit it using a local version of SIGMA (available from atlas. lanl.gov or 128.165.24.191) it will not necessarily be possible to merge this edited version back into the original map. Anyone wishing to contribute information, should contact Julia White (julia@mrc-hbgu.ucl.ac.uk) to find out the most efficient way of doing it. The best ways of entering large amounts of data (e.g. extensive cosmid contigs) are currently being explored, as are ways of interchanging data between GDB, AceDB and SIGMA.

\section{Tuberous Sclerosis Meeting}

\section{Associated With Chromosome 9 Workshop, 12 April, 1994}

Approximately 50 individuals attended the tuberous sclerosis meeting held after the chromosome 9 meeting, on the morning of 12 April, 1994. The first subject to be discussed was the cloning and characterization of the chromosome 16 (TSC2) gene. A round of congratulations was given to Drs Julian Sampson (Cardiff, UK) and Bart Janssen (Rotterdam, The Netherlands) for leading the European Consortium in cloning this gene. Dr Sampson reported that over half the genomic structure of the gene is now known (it has at least 26 exons) and he is now making the eDNA clones available to all interested individuals. More deletion mutations have been identified by the Welsh and Dutch groups; groups in Cambridge (UK), Boston (USA), and Houston (USA) have also identified mutations. Approximately $10 \%$ of patients studied so far have deletion mutations. No point mutations have been identified. Anna-Marie Frischauf (London, UK) reported on the cloning of the mouse homolog of the TSC2 gene (on mouse chromosome 17).

Efforts to clone the chromosome 9 gene are underway in many laboratories. A list of critical recombinants was compiled, and as has been the case before, several are in conflict with each other. A recombination in an affected individual placed TSC1 distal to D9S10 (Pitiot et al.), while in another study TSC1 was placed between ABL and ABO (Janssen et al.). The most consistent localization of the TSC1 gene is between D9S149 and D9S114, a genetic distance of approximately $3 \mathrm{cM}$ and a physical distance of approximately $1500 \mathrm{~kb}$. Moyra Smith (Irvine, USA) reported an apparent duplication of D9S66 in a sporadic case of TS, which was seen both by polymorphism studies and FISH. Sue Povey (London, UK) also saw evidence of a duplication for $\mathrm{DBH}$ in one small family. However, not all affected individuals in the family showed the duplication, and it was seen with only one DBH polymorphism. Andrew Green (Cambridge, UK) reported a deletion between D9S149 and D9S67 in one tumor, and Nicola Migone (Turin, Italy) reported deletions between ASS and D9S158 in another tumor. Moyra Smith also reported a candidate gene which spans D9S10 and D9S66 and which was homology 
to the mouse VAV gene. A list of six families apparently genetically linked to chromosome 9 . but including a person who excludes the consensus candidate region, was compiled.

A study of 21 families which had been assigned either as TSC1 or TSC2 found no consistent clinical differences between TSC1 and TSC 2 patients and also found no evidence for genomic imprinting (Povey et al.). Antonia Clarke reported that there is an increased rate of mental retardation in males, and that this is not related to the number of brain lesions.

Also discussed was the impact of the TSC2 gene cloning on patients and families. Ann Hunt (TSA, UK) reported that many families have contacted the TSC associations with questions about testing, and the most appropriate course of action was debated. It was generally agreed that although testing for TSC2 mutations could be done, only a minority would be identified, and that until much more is known about the mutations few people can yet be offered practical help.

The chromosome 9 workshop was made possible by the support of the U.K. Medical Research Council, DOE, NIH (NCHGR HG00886 and HG00598) and a grant from the E.C. through HUGO. The organisers would particularly like to thank John Attwood for the successful organization of computing arrangements for the meeting, and for his maintenance of the FTP server and the electronic mail list. We gratefully acknowledge the support of Sun Microsystems, who kindly loaned computing equipment for the SIGMA mapping exercise. We also thank David Judge of Cambridge University for making an Internet connection available during the workshop. We also appreciated the hard work of Andrew Green, Aris Astridinis, Thuy Nguyen and George Rebello which ensured that local arrangements ran smoothly, and of Dan Lindenbam in producing reports from GDB. We are grateful to Darlene Jackson, Nalini Pillay and Naomi Tobi for secretarial assistance. We thank the TS Association of Great Britain for sponsoring the TS Workshop.

\section{REFERENCES}

Attwood, J., Nahmias, J. \& Fairbrother, U. (1993). New data and the provisional CEPH consortium map of chromosome 9. Cytogenetics and Cell Genetics 64, 107.

Atrwood, J., Chiano, M. \& Collins, A. et al. (1994). CEPH Consortium map of chromosome 9. Genomics 19 , 203-214.

Brett, P. M., Le Bourdelles, B., See, C. G., Whiting, P. J., Attwood, J., Woodward, K., Robertson, M. M., Kalsi, G., Povey, S. \& Gurling, H. M. D. (1994). Genomic cloning and localization by FISH and linkage analysis of the human gene encoding the primary subunit NMDAR1 (GRIN1) of the NMDA receptor channel. Ann. Hum. Genet. 58, 95-100.

Church, D. M., Banks, L. T., Rogers, A. C., Graw, S. L., Housman, D. E., Gusella, J. F. \& Buckler, A. J. (1993). Identification of human chromosome 9 specific genes using exon amplification. Hum. Mol. Genet. 2 (11), 1915-1920.

Del Sal, G., Collavin, L., Ruaro, M. E., Edomi, P., Saccone; S., De: Valle, G. \& Schneider, C. (1994). Structure, function, and chromosome mapping of the growth-suppresising human homologue of the murine Gas1 gene. PNAS (USA) 91, 1848-1852.

Duclos, F., Rodius, F., Wrogemann, K., Mandel, J.-L. \& Koenig, M. (1994). The Friedreich ataxia region: characterization of two novel genes and reduction of the critical region to $300 \mathrm{~kb}$. (Submitted.)

Evdokiov, A., Webb, G. C., Peters, G. B., Dobrovic, A., Okeefe, D. S., Forbes, I. J. \& Cowled, P. A. (1993). Localisation of the human growth arrest-specific gene (Gas1) to chromosome bands $9 q 21.3-q 22$, a region frequently deleted in myeloid malignancies. Genomics 18, 731-733.

Kamb, A., Gruis, N. A., Weaver-Feldhaus, J., Liu, Q., Harshman, K., Tavtigian, S. V., Stockert, E., DaY III, R. S., Johnson, B. E. \& Skolnick, M. H. (1994). A cell cycle regulator potentially involved in genesis of many tumour types. Science 264, 436-440.

Kwitkowski, D. J., Armour, J., Bale, A. E. et al. (1993a). Report on the Second International Workshop on Human Chromosome 9. Cytogenet. Cell Genet. 64, 93-121.

Kwlatkowski, D. J., Dib, C., Sladgenhaupt, S., Povey, S., Gusella, J. F. \& Haines, J. L. (1993b). An index marker map of chromosome 9 provides strong evidence of positive interference. Am.J.Hum. Genet. 53 , $1279-1288$

OKa, K., Tzung, K.W., Sullivan, M. et al. (1994). Human very-low density lipoprotein receptor complementary DNA and deduced amino acid sequence and localization of its gene VLDLR to chromosome band 9 p 24 by fluorescent in situ hybridisation. Genomics 20, 298-300. 
Povey. S.. Sumth, M., HaInes, J. el al. (1992). Report on the First International Workshop on Chromosome 9. 1992. Ann. Hum. Genet. 56. 167-221.

Nobori. T., Miura, K., Wu, D. J., Lois, A., Takabayashr. K. \& Carsoy. D. A. (1994). Deletion of the crelindependent kinase-4 inhibitor gene in multiple human cancers. Vature 368. 753-756.

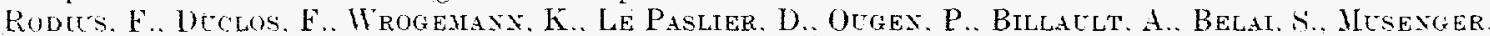
( . Brice. A. Dürr. A. Mrgatad. C.. Sircgo. G. Weissenbach. J.. Cohex. D. Hextati. F. Haxide M. B.. ILAxdel. J.-L. \& Koenig, M. (1994). Recombinations in individuals homozygous by descent localise the Friedreich ataxia locus in a eloned $450 \mathrm{~kb}$ interval. Am. J. Hum. Genet. 54, 1050-1059.

Sakai, J.. Hoshino, A., Takahashi, S., Mrura. Y., Ishi, H., Suzuki, H., Kawarabayasi, Y. \& Yamaioto. T. (1994). Structure chromosome location and expression of the human very low density lipoprotein receptor gene. J. Biol. Chem. 269, 2173-2182.

Suith. C. P., Weremowicz, S., Kanai, Y. et al. (1994). Assignment of the gene coding for the Human highaffinity glutamate transporter EAAC1 to 9p24: potential role in Dicarboxyllic Aminoaciduria and Neurogenerative disorders. Genomics 20, 335-336.

Stadler, W. M., Sherman, J., Bohlander, S. K., Roulston, D., Dreyling, M., Rukstalis, D., Olopade, O. I. (1994). Homozygous deletions within chromosomal bands $9 \mathrm{p} 21-\mathrm{p} 22$ in bladder cancer. Cancer Research 54, 2060-2063.

Sulisalo, T., Francomano, C. A., Sistonen, P., Maher, J. F., McKusick, V. A. de la Chapelle, A. \& Kattila, I. (1994). High resolution genetic mapping of the cartilage-hair hypoplasia gene in Amish and Finnish families. Genomics 20, 347-353.

Takahashi, E.-I., KoYama, K., Нiтомi, A., IтоH, H. \& Nakamura, Y. (1994). A high resolution cytogenetic map of human chromosome 9 : localization of 203 new cosmid markers by direct R-banding fluorescence in situ hybridization. Genomics 19, 273-275.

Tanaka, H., KoIke, R., Yuasa, T. et al. (1993). HGM93 abstract. Cytogenetics and Cell Genetics (In press).

Toda, T., Kanazawa, I. \& Nakamura, Y. (1993). Localisation of a gene responsible for Fukuyama type congenital muscular dystrophy to chromosome $9 q 31-33$ by linkage analysis. Nature Genetics 5, 283-286.

Verlander, P. C., Lin, J. D., Udono, M. U., Zhang, Q., Gibson, R. A., Mathew, C. G. \& Auerbach, A. D. (1994). Mutation analysis of the Fanconi anemia gene FACC. Am. J. Hum. Genet. 54, 595-601.

Walker, G. J., Walters, M. K., Palmer, J. M. \& HaYward, N. K. (1994). The MLLT3 gene maps between D9S156 and D9S171 and contains an unstable polymorphic trinucleotide repeat. Genomics $20,490-491$.

Whitiney, M. A., Saito, H., Jakobs, P. M., Grbson, R. A., Moses, R. E. \& Grompe, M. (1993). A common mutation in the FACC gene causes Fanconi anaemia in Ashkenazi Jews. Nature Genetics 4, $202-205$.

\section{DISCLAIMER}

This report was prepared as an account of work sponsored by an agency of the United States Government. Neither the United States Government nor any agency thereof, nor any of their employees, makes any warranty, express or implied, or assumes any legal liability or responsibility for the accuracy, completeness, or usefulness of any information, apparatus, product, or process disclosed, or represents that its use would not infringe privately owned rights. Reference herein to any specific commercial product, process, or service by trade name, trademark, manufacturer, or otherwise does not necessarily constitute or imply its endorsement, recommendation, or favoring by the United States Government or any agency thereof. The views and opinions of authors expressed herein do not necessarily state or reflect those of the United States Government or any agency thereof. 